\title{
Architectural lighting in search of identity: The environmental approach
}

\author{
Marina Sokolova ${ }^{1}$, and Marina Silkina ${ }^{{ }^{*}}$ \\ ${ }^{1}$ Moscow Institute of Architecture (State Academy), Department of Design of Architectural \\ Environment, 107031, Rozhdestvenka St., 11/4, building. 1, p. 4, Moscow, Russia
}

\begin{abstract}
This article examines the perception of architectural environment, and various approaches and methods of its light organization, including the design of evening illumination and objects of light design. Traced influence of the figurative discoveries of light art on light design, and the problems of the formation of individual light-plastic code of the urban environment as a means of manifesting the identity of the place are revealed.
\end{abstract}

Today, at the era of globalization, the disappearance of cultural and national differences, the problems of preserving identity come to the fore in many areas of an architectural project, and, most notably, in the design of the urban environment. Studies of visual perception of the environment, and awareness of environmental identity started in the 1960s with the work of American planner Kevin Lynch "The Image of the City" [1]. Today, the relevance of this problem is becoming all the more important.

The interest in the urban environment and the emergence of ideas for meaningful design of urban space were a "postmodern" reaction to the global paradigm of modernism functionalism that took dominant positions in the world architecture of the 1960s. The transition from modernism to postmodernism, from the lapidary nature of geometry to plastic complexity and organic, from the abstract form to the style quotation and contextuality, is a movement between the so-called "strong" and "weak" project orientations determined by the different type of relationship between the designer and the world (G. Courierova) [2, c. 60]. A "strong" installation is the purity and clarity of regular geometric composite construction, confirmed by the discoveries of modernism. The method of organic design, characteristic for the "weak" design setting, is directly opposite, thus emphatically concrete, reflexive, and historical. It is a direct-sensual experience of the flow of time. "Only by freeing ourselves of all abstractions, can we truly enter the living stream of experience, and expertly realize ... the concrete image of the world and life in its continuous formation and transformation" (cf. on 2, c. 77]. The postmodern design model is distinguished by the multidimensionality of values, leading to unpredictable innovation in plastic solutions [3].

The problems of complexity and multilayered spatial and temporal development of the urban environment, the treatment to the person, their relationship with architecture and space, the problems of contextual design and the need for changes formulated by Kevin Lynch

\footnotetext{
*Corresponding author: eremych@inbox.ru,marina.a.silkina@gmail.com
} 
(1960) [1] and Jane Jacobs (1961) [4] were further developed in the works of Christopher Alexander (1977) [5], Herman Hertzberger (1991) [6], etc. Ideas originated in the West were quickly picked up in the 1980 s by progressive Russian architects. In particular, Alexei Gutnov, Vyacheslav Glazychev, theoreticians Andrey Ikonnikov, Alexander Rappaport, Oleg Genisaretsky, Georgy Minervin and others, who changed in many respects the ideas of Russian designers about methods of working with urban environment, have developed a new method - the environmental approach.

Russian domestic researchers in the "general field" of the project culture have defined the fundamental difference between the concepts of "environmental space" and "architecture." In contrast with an architectural object with its completeness, static, invariability, the environment is characterized by such qualities as mobility, dynamism, disconnection, openness, and incompleteness. It is interpreted as a material, volatile subject-spatial interaction. The core of a design model of environment is the "metabolism" of people's interaction in specific conditions. The created "figurative construct," including architectural means, is calculated in advance as changing in time with "open", i.e., uncertain and indefinite, future. Unlike the architectural construct, the description of the environment is built during architectural practice solely by verbal means. (V. Glazychev) $[3,7,8]$.

Analysis of the properties of architecture and environment indicates their relation to fundamentally different languages of culture, and two different types of cognitive mechanisms - analytical and sensory, which points to the need for their interconnected developmental dominance. Differences lie in the field of the psychology of perception, the type of reaction of the consumer. In environmental design, the environment is not only the environment of something (or somebody) or a combination of elements or conditions, among which an object or a person. First of all, it is the interconnectedness and interpenetration of the components of the environment that affect its characteristics (V. Glazychev) $[3,7,8]$.

The relationship between environmental design and "easel" art is determined by an artistically oriented vision of project tasks. Like the painter the environmental designer tends to create not so much a building and its subject filling as its environmental state, the "atmosphere" that determines the imaginative beginning. The mediocre approach in design reveals the inter-permeability of types of artistic activity boundaries whose object of interest is the environment space. The mediocre approach, with its synthesizing "need to delve into everything" (V. Glazychev) [3,7,8], ensures "the cultural integrity of modern civilization" (G. Courierova) $[3,9,10]$.

If the term architectural "space" is disclosed as a continuum-pure duration and voidness, the term environmental space is understood as a particular case of space - an extended nonuniform materialized beginning where integrity is primary and dominates over dissection. The environmental space acts as a collection of space and material filling. It is characterized by priority of cohesion, leakage, and viscosity. The environmental space is a system of spiritual senses and material conditions contributing the dominance of the emotional principle over the rational, the synthetic over the analytic (I. Smekalov) [11].

The problems of professional relations with the environment are in the plane of the perception and interaction with the user. Physically, the architectural space is formed by what it is surrounded by, or by objects within it and visible in the light. And although we cannot explain by words what makes space particularly expressive, it can be determined by the height and perspective, giving a feeling of fullness without stiffness, an equilibrium between capacity and openness, and the combination of all kinds of factors, such as illumination, acoustics, a special ambience, people and, finally, the user's own mood, that affect the perception of space and emotion. "Architecture is a phenomenological discipline, which can be understood only at the moment when people move through the architectural space. If you turn your head, take a look, or turn the other way, you will see different space. You have had 
this opportunity to experience the space only because you have made a move. Also you will notice another texture of the surfaces and feel other materiality of the building depends on your move. Observation and analysis during (and after) these simple changes in one's position are the only way for true understanding and feeling of architecture. Referring to the book, "with even the greatest in the world of construction illustrations, you cannot understand what this building really is. Without being near it, you will not hear the melody that arises from its special acoustics, you will not feel its materiality and spatial energy, its unique play of light." (S. Holl) [cf. 12].

Studies of the integrity of visual perception, visual field, synthesis and differentiation of attention, problems of visual thinking and visualization revealed a similar device of instrumental-conceptual apparatus of medium and easel creativity (V.Rozin) [13]. Since the architectural environment is not only an object of functional use, but also an object of sensory experience, it must be created not only on the basis of technical calculations but, first of all, taking into account the aspects of perception and "empathy", formed by means of artistic expressiveness, or figurative language. For the first time in relation to architecture the notion of "language" was introduced by Charles Jenks in his book The Language of the Architecture of Postmodernism [3, 14].

Kevin Lynch proposed conscious designing of "image" of public spaces, combining psychology and sociology with urban planning and architecture. For him, primary was the problem of perception of urban environment by man, its comprehension and comfortable orientation among it - the formation of clear, readable and at the same time unique images represented by universal elements revealed in the general structure of the city: paths, borders, areas, nodes, [1]. Rethinking the problems of town planning Alexei Gutnov formulated more general terms that define the structure of spatial organization: "frame", "fabric", "plasma". He paid special attention to changing subject content of the urban environment with design objects - including urban furniture, navigation and lighting systems [15]. And if the "fabric" basically determines the areas, forms the boundaries, contains the dominants (the landmarks), and the "skeleton" basically forms the paths and nodes, the "plasma" creates elusive combination of objects and spaces into single environmental integrity.

In darkness, the illumination undoubtedly plays a dominant role in shaping the image of the urban environment perceived by the inhabitants. The environment perception is offered through the "flashing" of individual objects (architectural lighting) and the "manifestation" of the entire structure (functional lighting). "Background" lighting is of great importance (e.g. windows' light in buildings). Functional lighting is subordinated to the existing road and transport structure and does not create anything in itself, but architectural, landscape and information lighting shapes the unique environment that a person perceives, and by means of which, the "image of the city" which is formed in his consciousness as the carrier-reflection of his identity [16].

Unfortunately, today there is a dangerous trend of unification in the design of urban lighting, including systems of light navigation. Many lighting and navigation projects for large cities differ little from the point of view of the formation of the environmental state and the appearance of the objects. Such a light environment does not aim to identify, preserve, manifest, exacerbate or form a new identity conditioned by the environmental context. It is unlikely that this return to unification and globalization can be justified by the need to ensure a universal reading of the spatial arrangement and orientation information. Universalism leads to emotional "deafness," the loss of environmental historical memory, the most fragile component of urban fabric. Ideas to start a project from scratch are absurd and disastrous, since under the pretext of having to start from the beginning, existing buildings are being destroyed and the empty space is filled with practically "sterile" structures. The different meanings of everything that has taken place are similar to the old layers of paint lying one 
over the other. In their entirety, they form a primer for us to know where a new layer can be placed, a new meaning that will change the whole a little. This process is an evolutionary process of transformation, whereby the obsolete meanings become the background for the creation of a new one. With the help of such a dialectical process, a continuous thread between the past and the future is preserved, and the connection of times is realized $(\mathrm{H}$. Hertzberger) [17]. Of course, the content that is brought into the urban environment today should not be excessively individual or active, but it must nevertheless take into account the environmental context, respond to it, solve the problems of manifesting the nature of the environment, and be the bearer of a special "spirit of place".

Through a special spatial character and a system of landmarks, and through a certain essence, an intangible substance called the "spirit of the place" is cultivated, in accordance with which our ancestors' lives proceeded, and the way they perceived their habitat. In today's economic and cultural globalization the problem of the loss of identity is becoming especially urgent, but there are the differences between places and cities that give them special value, thus provoking us to move through spaces - to travel. In addition to orienting in space, it is important for people to identify themselves with a certain place, the features of which that are manifested by their spatial arrangement and a set of characteristic plastic qualities. The object-spatial relations perceived during the day and in the dark are replaced by light ones which can echo the existing architectural structures, and create another composite picture. Architectural lighting, contributing to the formation of the "night image of the city" and orientation in it, is most relevant for the historic city center. Highlighting monuments of architecture suggests the perception of the night city as a more articulated, aggravated image of the city of the day, where historical features become dominant environmental reference points. Cities are associated, as a rule, with their signature architectural objects, though the means for creating their evening image differ little: in Paris the Eiffel Tower is lit, in Moscow the Kremlin, and in St. Petersburg the Peter and Paul Fortress. These are the image objects with which we actually identify cities. The methods of such architectural "flashing" are also almost always uniform. Thus, evening lighting only shows the existing architectural and town-planning features of the city.

Where is the inspiration for new solutions? Undoubtedly, in the historical context, landscape, planning structure, national and regional cultural and plastic tradition, color preferences, from which new solutions must grow, form a certain composite and imaginative integrity, and thus new landmarks and bearing features of the environment identity. Among the most characteristic examples of the designer's interaction with the components of the environmental identity we can mention Paris where the signs addressed are turned into objects of souvenirs, as well as the recognizable signs on the houses in Rome, and the sign of the metro in London. So the element of the orientation system goes beyond its function and environmental visual image, and becomes an object identified with the city, its nonarchitectural symbol, which has a relationship to the brand of the city and the formation of identity in the fashionable branding of territories today.

While designing a light design solution it is important to set tasks not to create a universal, often contradictory new environment structure, but to show or adjust the existing urban environment through the light layer using non-standard and even radical design solutions. An example is the light memorial on the site of the destroyed towers of the World Trade Center (Twin Towers) in New York. Of course, this is not the creation of a new identity, it is a manifestation of the "spirit of place" through a light "architecture" - installation. A similar solution showing the lost is Roger Narboni's project for São Paulo (Brazil), where the light master plan for the entire city is built on the manifestation of the historical landscape and the invisible rivers of the Spirits. So in Moscow it is possible to "restore" the walls of the White 
City, and on Neglinka Street and Kuznetsky Most Street, to "return" Trubnaya Square to the image of a light river - Neglinnuyu, hidden underground in the early 19th century.

Perception is the ability to release (extract) certain aspects from context to place them in a new context. Each new idea begins with observing things differently. Observing the architecture of other times or places, it is necessary to direct our eyes from the objects to the place which create the form, to look through the definiteness of the form revealing the essence of the place and thus shifting the accent from the architecture to what the environment is, and to discover its influence on the succession of generations and cultures. Although we do not control our impressions, we can, at least, develop our eyes, gaining the habit of fixing things on paper. Among all the possibilities of reproducing the subject, the drawing is the most consistent with this goal, and is more effective than, for example, photographs that everyone takes from time to time. In many cases, photography is the most appropriate means to present the situation objectively. However, the dignity of the picture is that, looking at things with greater accuracy and, above all, becoming more rigorous to what seems important, the severity in fixation will increase. It then becomes possible, having got rid of unnecessary details, to fix the very essence, and the formula of the object. The only accessible way out of our own limitations is the development of figurative thinking, the connection to the riches of collective memory. Turning back to fundamental, which is unaltered components, we discover the existence of common features - archetypes in various objects. And thus we find the "cross-section of everything" - an unchanging element at the base of all examples that always recalls memories, can be the starting point form. Today the means of the whole array of the past are endless. Elements freed from specific time frames have more general meaning and appear in different guises, obviously because they can be related to basic human values that are preserved, albeit with varying emphasis and in different style languages preserving the basic generative grammar (H. Herzberger) [17].

How can you analyze the environment? Architectural forms and their location in space can be likened to composition of their primary elements. In this abstract figure, with the help of the semantic component of the elements themselves, those invisible characteristics of the place, its spirit, which predetermined the location of large and small architectural forms in space and the growth in it of objects of the natural landscape, are concentrated. To sum up, this drawing can be called a plastic equivalent of the place visualized by means of light technologies in the dark.

Examples of growing an environmental solution from the context can be seen in a number of architectural projects today, for example, the project of the Cultural Center for Santiago de Compostela, created by the architect Peter Eisenman. As Eisenmann himself says, he always tried to grow his buildings from the ground, so that they would form a single whole without breaking the connection with it. The idea of layering various tracks found on the site, not only visual, but also historical, symbolic, abstract, hypothetical and so on, has been developed by Eisenman long ago and consistently. The architect was influenced greatly by French philosopher Jacques Derrida, author of the theory of deconstruction, denying the existence of an absolute beginning and arguing that any beginning is preceded by a trace or a wreath of traces. Derrida argued: "There is nothing that would exist before anything else. There is no one truth. There is no absolute beginning. Everything opened before the tracks had begun. Before there was something, there had been a trace of something. Before there was something, this something had not been. Absence always precedes presence, because there would be no presence if there was not originally absence "[18, 19].

Eisenman's team identified four such tracks on the site: the topography of the hill on the construction site assigned to the new complex; a network of streets of the historic center of Santiago de Compostela; an abstract Cartesian network and a symbolic sign of the city - a shell of a shellfish. Then all these unrelated tracks were combined into a complex plexus to 
create an imaginary site that eventually became real. In other words, the beginning of the project was not a physical site allocated for construction, but traces, according to Derrida's theory and Eisenman's interpretations, found on this site and around. It is interesting to note that the intriguing tectonic form arose independently of the planned functions of the complex in the process of the artistic combination of abstract trace diagrams into a single sculptural landscape-environmental formation. The cast of plastic solution was a three-dimensional wooden layout, which inspired the customer to implement this particular design intent [18, 19].

Eisenman believes that a person in the architectural space perceives its organization and its device by his mind, and the vague sensations of the space by the senses. Describing the features of his own creative process, Eisenman calls geological, topological, social, economic, technical diagrams taken from the plot and forming project layers that form the structure and body of the building, such as its spelling, morphology and syntax, and what eventually becomes an architectural space, poetry born from heart. Where the mind ends and the heart begins is almost impossible to be determined. However, the traces of these diagrams, "organized by reason", in the inner space of the complex - the inclusion of a dark stone in the floor, the relief drops of the fragments of the ceiling - are perceived precisely by heart and, more likely, even by artistic feeling, as a single multilayered spatial composition $[18,19]$.

Another architect, Steven Holl, also believes that it is necessary to create a new one by imposing simple components on each other. Components can be a function, a form, a social aspect, a historical fact, a natural or social phenomenon. Holl's architecture is distinguished by the project translation of these semantic components into an artistic and plastic invention - the geometric form, the principle of compositional division, and the use of material and color. The materialization of the architectural idea at the stage of sketching in a mock-up or drawing with elements of painting translates it into an artistic technology, which leads to a clearly read design of the architectural structure, and transparency of the means used. As a result, the pleasure of the viewer in easily guessing the plastic form responses to the context or function assignments. "I believe that architecture needs to be a continuation of the place, and it needs to meet the goals that it is laid down. My first book, "Anchoring," explains the relationship of the structure to the place in which it is located, with its culture and metaphysical principles. If the author's architectural concept ... can penetrate deeper into the cultural and spiritual aura of the place, then it enriches it with a new cultural significance, individual and modern ... It is important to hook on the idea that hovers in the air of each place. It can be anything: stories passed from mouth to mouth, living folklore, inimitable humor "(S. Holl) [op. 12].

Is it possible to use this method in the design of night lighting? This design does not exist in isolation from the general cultural field. It always follows the discoveries, whether they are the discoveries in the field of art or scientific and technical innovations. It admits everything that can affect the form and function, but it is the form that determines our visual perception of the objective world. In the field of light design, the choice of certain means of expressiveness is not accidental, but largely formed under the influence of artists and sculptors who began to work with light as a means of creating an artistic work - "light sculpture", when light does not illuminate an object, but becomes an "object" itself.

If in the early 20th century light was used more as a source - artists were more concerned with shadows, and reflection effects (Marcel Duchamp, László Moholy-Nagy), then in the 1960 s the source itself. Even later the light itself becomes an object of art, which was due to the emergence of new technologies, in particular the wide use of neon, light projections. The artistic means created contribute to the compositional organization of the environment in modern urban design, turning not only individual small forms but also large urban spaces 
into art objects. This was promoted by such masters as Lucio Fontana, Dan Flavin, Francois Moreliet, James Turrell, Bruce Nauman, and contemporary artists such as Massimo Uberti, Carlo Bernardini, Björn Dahlem, and Jim Sanborn et al.

Unlike other types of art, abstract plastic arts, including design of the light environment, convey sensory images through the associative possibilities of means of expressiveness - the types of composite connections, color-inverse relations, the configuration of lines, and forms of rhythm, etc. As examples of modern urban design show, solutions directly related to the language of art, which are successive to artistic discoveries of the 20th and 21 st centuries, are able to successfully interact with the subject but spatial environment, complementing it organically. Small architectural forms, equipment elements, navigation systems, can become art objects, like city sculpture creating a memorable visual image of the environmental fragment (street, quay, square, etc.) both in the light and in the dark.

The use of light as an independent composite tool are traced in the modern design of urban equipment and elements of improvement. The urban environment easily "admits" these point-like, accenting, contrasting light-color solutions that do not require consistency with all other components of the light environment, and functional and architectural lighting. The compositional structure of such decisions, as a rule, is determined by the plasticity of the elements of urban design themselves. It emphasizes and manifests such plasticity and has a distinct light structure, which creates prerequisites for the development of the identity of the territories and the formation of their visual image in the dark.

The connection between light art and modern lighting solutions can be found in the concept of the light "gateway" for Paris - the "Paris Crown" Lighting Master Plan (France) by the French lighting designer Roger Narboni. This approach is also illustrated by lighting solutions for Finsbury Avenue Square in London (United Kingdom) and Plaza del Torico in Teruel Teruel (Spain), where the lines, in the first case, structure space, and, in the second, introduce free dynamics of light "strokes". Other examples of "light strokes" are a solution of light guides embedded in the pavement, lawns and benches of the University Entrance Square of the Ben-Gurion University of the Negev in Beer-Sheva, Israel; a solution of light lines located at a slight angle to each other, resting in the High Line Park in New York, USA; and a dynamic broken line running along the ends of the seating facility that organizes the public space in Hamburg, Germany.

Using plastic language, it is possible to find a picture of environmental identity for each fragment of a city or the city as a whole. Growing up from different historical and geographical circumstances, the cities have a unique pattern of planning fabric and a special character. Just to name a few examples: the two high banks of Prague, connected by "lacing bridges"; the clinging to the water "sink" of Amsterdam; spreading "ice floes" of the islands of Stockholm united by the structure of streets; and the "cuttings" of Osman that cut through the "goat trails" of Paris.

What can we say about Moscow in this connection? At the level of the general plan, the color is working - there is the red triangle of the Kremlin in the center; the green ring of the Boulevard Ring; and the multi-colored ring of Sadovaya streets. Bypassing the triangle, the ring crosses the blue snake of the Moscow River, creating an eye-orienting road. The next layer of the city structure is the rays that organize the city fabric.

Let us now turn to what can be called the deep characteristics of Moscow as the ancient capital. The so-called "Russian spirit" in Moscow consists of simplicity and geometry of white stone construction, wooden architecture, architecture of classicism, constructivism of the 1920 s, monumentality of the mid-20th century, and the rapidly developed new quarters. In the basis are the pattern and the constructor. On top of that is the general characteristic of Moscow at all times, which is "merchant decoration" (decor, details), brightness, bustle, fairness, as well as a constant desire to break the composition of the foreign object. All these 
lead to a common collage of the environment. Thus, in the course of development, a highrise tower or any other construction of a different style may appear, set obliquely, non-scale, and foreign in the city. And in some cases, constant changes in the terrain lead to a combination in the environment with fragments of completely unrelated stylistics, scales, heights, and geometries. Thus, a kind of environment "out of nothing."

Translating previous reflections into the language of abstract forms, one can obtain a whole series of light solutions, using the general light-plastic code of the place, i.e. "structure and collage". This helps to create a systematically organized light frame of a certain place, in which other elements - complex, dynamic, multicolored, and organically-smooth, can be found. In another situation, the initial complexity, contrast, collage of the medium can lead to a contrasting connection of the fragments of the light solution, thus a string of different compositions combined by some limiting principle (number, size, height of the light pattern).

Why is it so expressively effective that there can be plastic and compositionally clear light accents in the environment of a modern city? In the situation of "visual noise", which exists in most cases as a result of spontaneous human actions at different times, they create a certain frame of perception of space in the evening and structure space. They are most noticeable in chaos because they are extremely contrasting with the environment.

Is it expedient to find another way? Is it really necessary to give light the ability to form a new identity, both for local urban spaces and cities as a whole so as to create urban spaces where a unique light solution itself becomes an "environmental magnet"? Is there a danger that such a radical use of lighting will destroy the existing architectural spaces? Can light being used not only as a means of illumination, but also as an independent component of the environment, as a light object, sculpture, architecture, space, be self-sufficient? Should light solutions follow the device of the environment, respond to it or be opposed to it? Can these decisions be made randomly? Will this help the formation of new images with quality and comfort of orientation in space? One thing is clear: interest in such radical decisions is much in focus today. Therefore, an experiment and development of new design principles for the light organization of the urban environment, which grow out of context but do not deny the possibility of creating a new identity and environmental magnets in the evening city environment, is necessary. How is it possible to create a design solution as put in the words of the architect Peter Eisenman: "To be there, to walk there -- it makes you be amazed" [19].

Designing a light-plastic space is a special creative task. Attention to the peculiarities of a particular place, to its landscape, cultural-historical, social and other contexts, to its "spirit" requires a light designer to be particularly sensitive. An individual approach to light design becomes a necessary condition today for preserving the unique face of each place and each city.

\section{References}

1. K. Lynch, The Image of the City (The MIT Press, 1960)

2. G.G. Kurerova, Italyanskaya model dizayna [Italian Design Model](Biblioteka dizaynera. Seriya Zarubezhnyiy dizayn, Fotopoligraficheskiy tsentr VNIITE, Moscow, 1993)

3. M. A. Sokolova, Sovremennyiy plasticheskiy yazyik v obuchenii arhitektora-dizaynera: Uchebnoe posobie [Modern plastic language in the training of the architect-designer: Textbook] (Arhitektura-S, Moscow, 2016)

4. J. Jacobs, The Death and Life of Great American Cities (Random House, New York, 1961)

5. C. Alexander, A Pattern Language: Towns, Buildings, Construction (Oxford University Press, USA. 1977) 
6. H. Hertzberger, Lessons for Students in Architecture (NAi010 Publishers, Rotterdam, 1991, 2005)

7. V.L. Glazyichev, Yazyik i metod hudozhestvennogo proektirovaniya [Language and method of artistic design], Dekorativnoe iskusstvo, 11 (1973)

8. V.L. Glazyichev Sotsialno-ekologicheskaya interpretatsiya gorodskoy sredyi [Socioecological interpretation of the urban environment] (Nauka, Moscow, 1984)

9. G.G. Kurerova Ekologicheskaya orientatsiya $v$ sovremennoy proektnoy kulture Zapadnoy Evropyi // Sotsialno-kulturnyie problemyi obraza zhizni i predmetnoy sredyi [Ecological orientation in the modern project culture of Western Europe // Sociocultural problems of the way of life and the subject environment] Trudyi VNIITE, Tehnicheskaya estetika, Vol. 52, p. 85 (1987)

10. G.G. Kurerova Proektnaya kontseptualistika 80-h godov: novoe myishlenie $i$ «inoe» myishlenie // Tvorcheskie napravleniya v sovremennom zarubezhnom dizayne [Project conceptualism of the 80s: new thinking and "other" thinking // Creative trends in contemporary foreign design], Trudyi VNIITE, Tehnicheskaya estetika, Vol. 60, pp. 22-44 (1990)

11. I.V. Smekalov Rol zhivopisi v proektnoy kulture sredovogo dizayna: Avtoref. dis. kand. iskusstv.: 17.00.06 [The role of painting in the project culture of environmental design: Author's abstract. dis. Cand. Arts: 17.00.06] pp. 22-44 (VNIITE, Moscow, 2009)

12. S. Holl, zdes i dalee tsit. po: Nevlyutov M. Prakticheskaya fenomenologiya Stivena Holla [Here and below. by: Nevlyutov M. Practical phenomenology of Steven Holl] from https://archi.ru/world/66898/prakticheskaya-fenomenologiya-stivena-holla

13. V.M. Rozin, Vizualnaya kultura $i$ vospriyatie (Kak chelovek vidit $i$ vosprinimaet mir) [Visual culture and perception (How a person sees and perceives the world)] (Editorial URSS, Moscow, 1996).

14. M. A. Sokolova, Modern visual language and plastic education, AMIT 4 (13) from http://www.marhi.ru/eng/AMIT/2010/4kvart10/sokolova/abstract.php (2010)

15. A.E. Gutnov, Evolyutsiya gradostroitelstva [The Evolution of Urban Planning] (Stroyizdat, Moscow, 1984)

16. M.A. Silkina, Light reference points in a night city environment//Light \& Engineering. Vol. 23, No. 2, pp. 29-33 (2015)

17. H. Hertzberger, Space and the Architect: Lessons for Students in Architecture 2, (010 Publishers. Rotterdam, 2000)

18. V. Belogolovskiy V krasote li schaste? Beseda s Piterom Ayzenmanom [In beauty is happiness? Conversation with Peter Eisenman], Arhitekturnyiy Vestnik, 5 (2009)

19. P. Eisenman. Lektsiya Pozdniy stil [Lecture Late Style] 29.05. 2010. TsDH. Vyistavka ArhMoskva (2010) 